CLINICAL STUDY

\title{
Serum sclerostin levels in men with idiopathic osteoporosis
}

\author{
B Lapauw ${ }^{1,2}$, S Vandewalle ${ }^{1,2}$, Y Taes ${ }^{1}$, S Goemaere ${ }^{2}$, H Zmierczak ${ }^{2}$, J Collette ${ }^{4}$ and J M Kaufman ${ }^{1,2,3}$ \\ ${ }^{1}$ Department of Endocrinology, ${ }^{2}$ Unit for Osteoporosis and Metabolic Bone Diseases and ${ }^{3}$ Laboratory for Hormonology, Ghent University Hospital, \\ De Pintelaan 185, 6K12 I.E. B-9000 Ghent, Belgium and ${ }^{4}$ Bone and Cartilage Markers Laboratory, Unilab Lg, CHU Sart Tilman, University of Liège, \\ Liège, Belgium \\ (Correspondence should be addressed to B Lapauw at Department of Endocrinology, Ghent University Hospital; Email: bruno.lapauw@ugent.be)
}

\begin{abstract}
Objective: Sclerostin inhibits osteoblast differentiation and bone formation. If aberrant sclerostin action is involved in less efficient bone acquisition in men with idiopathic low bone mass, this might be reflected in higher serum sclerostin levels.

Methods: In 116 men with idiopathic osteoporosis ( $\leq 65$ years old), 40 of their sons and healthy controls, areal bone parameters were measured using dual-energy X-ray absorptiometry, and volumetric and geometric bone parameters were measured using peripheral quantitative computed tomography. Serum analytes were measured using immunoassays and estradiol $\left(\mathrm{E}_{2}\right)$ levels using liquid chromatography-tandem mass spectrometry.

Results: Men with idiopathic low bone mass had lower levels of sclerostin than the controls $(0.54 \pm$ 0.17 vs $0.66 \pm 0.23 \mathrm{ng} / \mathrm{ml} ; P<0.001)$. In both groups, sclerostin levels were strongly associated with age; when adjusting for age, no associations with anthropometrics were observed $(P>0.14)$. In multivariate analyses, sclerostin levels displayed a positive association with whole-body bone mineral content (BMC) and areal BMD (aBMD), as well as with trabecular and cortical volumetric bone mineral density (vBMD) at the tibia in the probands. No clear associations were observed in the control group, neither were sclerostin levels associated with BMC at the radius or lumbar spine (all $P>0.11$ ). Testosterone, but not $E_{2}$, was inversely related to sclerostin levels in the probands. No difference in sclerostin levels was found in their sons when compared with their controls.

Conclusion: Lower rather than higher serum sclerostin levels in the probands with idiopathic low bone mass suggest that aberrant sclerostin secretion is not involved in the pathogenesis of low bone mass in these subjects.
\end{abstract}

European Journal of Endocrinology 168 615-620

\section{Introduction}

Osteoporosis and related fractures are prevalent and lead to increased morbidity and mortality in both sexes (1). In about half of men with osteoporosis, no clear pathogenic cause can be established (2). Our previous findings in a family-based study of men with idiopathic osteoporosis concurred to indicate the existence of a familial defect in the acquisition of bone mass and size, involving both trabecular and cortical bone.

Sclerostin, a glycoprotein secreted by osteocytes partially in response to mechanical loading, is a strong negative regulator of osteoblast differentiation and bone formation through antagonizing effects on the Wnt/ $\beta$-catenin signaling pathway $(3,4)$. Serum levels of sclerostin increase with aging, have been reported to be positively related to overall bone mass, and sex differences have been described $(5,6,7,8)$. Furthermore, observational and interventional data suggest that circulating sclerostin levels are modulated by estrogen exposure $(6,7,8,9)$. In our family-based study, we reported lower serum estradiol $\left(E_{2}\right)$ levels in men with idiopathic low bone mass, suggesting an estrogen-related factor in the pathogenesis of male idiopathic osteoporosis. In addition, these men displayed lower serum pro-collagen 1 amino-terminal propeptide (P1NP) levels, reflecting less bone formation $(10,11)$. We therefore hypothesized that lower bone mass in these men might result from constitutionally higher sclerostin levels and/or action, possibly linked to lower $\mathrm{E}_{2}$ exposition at the tissue level.

\section{Materials and methods}

\section{Subjects}

Male study subjects $(n=116)$ were diagnosed with idiopathic low bone mass using the following inclusion criteria: age $\leq 65$ years at presentation and areal BMD (aBMD) Z-score $\leq-2.0$ at the lumbar spine or proximal femur. Extensive clinical and laboratory investigations excluded secondary causes of low bone mass. All sons were invited to participate without any 
DXA-based selection. Subjects with a history of hyperthyroidism, metabolic bone disease, delayed puberty, current or past alcohol consumption of $\geq 5$ units/day more than once weekly, malabsorption, hemochromatosis, renal or gonadal dysfunction, malignancy or chronically treated with glucocorticoids, levothyroxin, or (anti)androgens were excluded. For each proband and son, a gender- and age-matched $( \pm 2$ years) control was recruited among healthy volunteers without a family history of osteoporotic fractures. None had a history of disease or medication use interfering with bone metabolism, or were heavy smokers $(\geq 40$ pack-years) or drinkers ( $\geq 5$ units/day more than once weekly). Physical activity was assessed by recording the weekly frequency of recreational and/or professional activities and scored as proposed by Baecke et al. (12). All participants gave written informed consent for participation in this study, approved by the ethics review board of the Ghent University Hospital.

\section{Anthropometrics, soft tissue composition, and areal bone parameters}

Participants' body weight was measured to the nearest $0.5 \mathrm{~kg}$ in light indoor clothing without shoes. Standing height was measured to the nearest $0.1 \mathrm{~cm}$ using a wall-mounted Harpenden stadiometer. Areal bone parameters at the lumbar spine, proximal femur (total hip and neck), radius (non-dominant side), and wholebody composition were measured using DXA: QDR-2000 (first 68 matched couples; software version 7.20) or QDR-4500A (all subsequent couples; software version 11.2.1; Hologic, Inc., Bedford, MA, USA); all matched couples were measured on the same device and devices were cross-calibrated. Vertebrae with apparent fractures were excluded from the analysis; coefficients of variation $(\mathrm{CV})$ were $<1 \%$ for daily spine and weekly whole-body phantom measurements.

\section{pQCT measurements}

In this ongoing study, peripheral quantitative computed tomography (pQCT) measurements were added and extended during the study course and lack for some of the early recruited probands and their sons. Crosssectional slices $(2.0 \mathrm{~mm}$ thick; voxel size $0.4 \mathrm{~mm})$ at the metaphysis (at $4 \%$ of bone length from the distal end of the radius) of the non-dominant forearm (all participants) and the lower leg (probands only, 66 couples) were taken to determine trabecular volumetric bone mineral density (vBMD) by pQCT (XCT2000; Stratec $\mathrm{GmbH}$, Pforzheim, Germany). Cortical bone parameters were determined at the midshaft of the non-dominant forearm (probands, 70 couples and sons, 23 couples) and the lower leg (probands, 66 couples) at 33 and $38 \%$ of bone length from the distal end of the radius and tibia respectively. Analyses were performed using the manufacturer's software (version 5.4). The cross-sectional area of the radius/tibia was determined after detecting the outer bone contour at a threshold of $280 \mathrm{mg} / \mathrm{cm}^{3}$. The threshold was set at $180 \mathrm{mg} / \mathrm{cm}^{3}$ for determining trabecular vBMD and at $710 \mathrm{mg} / \mathrm{cm}^{3}$ for cortical bone. Cortical thickness and the endo- and periosteal circumference were estimated using the circular ring model in which the shaft of a long bone is assumed to be an ideal cylinder.

\section{Laboratory measurements}

Venous blood was obtained between 0800 and $1000 \mathrm{~h}$ after overnight fasting and serum stored at $-80^{\circ} \mathrm{C}$ until analysis. Samples from the probands, their sons, and respective controls were measured in a single assay run. Commercial immunoassays were used to measure serum leptin (Linco Research, Inc., MO, USA), P1NP, total testosterone, SHBG (Orion Diagnostica, Espoo, Finland), C-terminal telopeptides of type 1 collagen (CTX; Biomedica Medizinprodukte GmbH, Vienna, Austria), bone-specific alkaline phosphatase (bAP; Beckman Coulter, Inc., Fullerton, CA, USA), osteocalcin (Nordic Bioscience Diagnostics A/S, Herlev, Denmark), and sclerostin (TECOmedical AG, Sissach, Switzerland). For sclerostin, the limit of detection was $0.12 \mathrm{ng} / \mathrm{ml}$ and the limit of quantification $0.20 \mathrm{ng} / \mathrm{ml}$; intra-assay $\mathrm{CV}$ was $<15 \%$ for levels between 0.20 and $0.50 \mathrm{ng} / \mathrm{ml}$ and $<6 \%$ for levels $>1.00 \mathrm{ng} / \mathrm{ml}$ and inter-assay $\mathrm{CV}$ was $<6 \%$ for levels $>0.50 \mathrm{ng} / \mathrm{ml}$. Serum $\mathrm{E}_{2}$ was determined by liquid chromatography-tandem mass spectrometry as described previously (13). Free testosterone and $\mathrm{E}_{2}$ were calculated from testosterone, $\mathrm{E}_{2}$, SHBG, and albumin concentrations using equations based on the mass action law $(14,15)$. For all measurements, intra- and inter-assay CV were below 10 and $15 \%$ respectively. Assays were performed at the Laboratory for Hormonology at the Ghent University Hospital except for serum sclerostin, which was assayed at the Bone and Cartilage Markers Laboratory, Unilab Lg, CHU Sart Tilman, University of Liège. Kidney function was determined by the calculation of estimated glomerular filtration rate (eGFR; $\mathrm{ml} / \mathrm{min}$ per $1.73 \mathrm{~m}^{2}$ ) according to the MDRD formula.

\section{Statistical analysis}

If normally distributed, variables were described as mean \pm s.D., and as median (1st-3rd quartiles) otherwise. If necessary, variables were transformed (natural logarithmic) to meet the required model assumptions. Comparisons between groups were performed using independent sample $t$-tests and ANCOVAs to account for potential confounding by age, body weight, or height. Univariate and age-, weight-, and height-adjusted associations between sclerostin and different patients' characteristics were explored using multiple linear regression models, with effect estimates reported as standardized regression coefficients $(\beta)$. The level indicating 
Table 1 General and bone parameters. Data presented as mean \pm s.D.

\begin{tabular}{|c|c|c|c|c|c|c|}
\hline & $\begin{array}{c}\text { Probands } \\
(n=116)\end{array}$ & $\begin{array}{l}\text { Controls } \\
(n=116)\end{array}$ & $\boldsymbol{P}^{\mathrm{a}}$ & Sons $(n=40)$ & $\begin{array}{c}\text { Controls } \\
(n=40)\end{array}$ & $P^{a}$ \\
\hline Age (years) & $45.3 \pm 12.9$ & $46.0 \pm 13.1$ & 0.68 & $28.6 \pm 6.0$ & $28.8 \pm 6.4$ & 0.91 \\
\hline Weight $(\mathrm{kg})$ & $74.4 \pm 9.3$ & $82.3 \pm 11.6$ & $<0.001$ & $73.5 \pm 11.3$ & $79.1 \pm 10.0$ & 0.087 \\
\hline Height $(\mathrm{cm})$ & $174.4 \pm 6.3$ & $177.1 \pm 6.5$ & 0.002 & $180.8 \pm 6.7$ & $180.8 \pm 6.1$ & 0.99 \\
\hline Trabecular vBMD at radius $4 \%\left(\mathrm{~g} / \mathrm{cm}^{3}\right)^{\mathrm{b}}$ & $183 \pm 37$ & $226 \pm 43$ & $<0.001$ & $217 \pm 32$ & $242 \pm 38$ & 0.036 \\
\hline Cortical vBMD at radius $66 \%\left(\mathrm{~g} / \mathrm{cm}^{3}\right)$ & $1191 \pm 50$ & $1207 \pm 22$ & 0.004 & $1178 \pm 59$ & $1197 \pm 46$ & 0.32 \\
\hline Cortical bone area at radius $66 \%\left(\mathrm{~cm}^{2}\right)$ & $94 \pm 13$ & $103 \pm 13$ & $<0.001$ & $97 \pm 10$ & $105 \pm 12$ & 0.072 \\
\hline
\end{tabular}

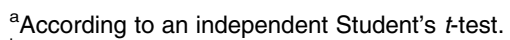

${ }^{b}$ pQCT data only available for 23 of the sons.

statistical significance was $<0.05$ (two-tailed). Statistical analyses were performed using SPSS (version 19.0; SPSS, Inc.).

\section{Results}

\section{General characteristics}

As reported previously (11), men with idiopathic osteoporosis had a lower body weight, height, lean, and fat mass than the age-matched control subjects. Their bone mass deficit involved trabecular and cortical bone density as well as cortical bone size (Table 1), and these men presented lower serum levels of $\mathrm{E}_{2}$ and free $\mathrm{E}_{2}$, in part due to higher SHBG levels (Table 2). Regarding sclerostin, lower serum levels were observed in men with idiopathic osteoporosis when compared with their controls (Fig. 1), whereas no difference was found in their sons when compared with their respective controls. The results were not essentially different when only considering the affected sons (data not shown). When adjusting for age and whole-body $\mathrm{BMC}$, the observed between-group difference in serum sclerostin levels between the probands and their controls was no longer significant $(P=0.13)$.

\section{Relationship with serum sclerostin levels}

In both probands and healthy controls, sclerostin levels were strongly and essentially similarly related to age (Fig. 2). In the control group, positive associations between sclerostin levels and body weight, BMI, and total fat mass were no longer significant after adjusting for age, whereas positive associations with leptin levels persisted even after controlling for weight or body fat mass (probands, $\beta=0.341 ; P=0.062$ and controls, $\beta=0.265 ; P=0.037$; Table 3).

When adjusting for age, weight, and height, sclerostin levels in the probands were positively related to whole-body aBMD and BMC, as well as to trabecular vBMD and BMC and cortical vBMD at the tibia. In the controls, sclerostin levels were associated with aBMD at the proximal femur and tended to be positively related to cortical vBMD $(\beta=0.228 ; P=0.057)$. No associations were found with trabecular or cortical bone parameters at the radius, neither were sclerostin levels associated with areal bone parameters at the radius or lumbar spine in either group (all $P>0.06$ ). Except for the endosteal circumference at the tibia $(\beta=-0.23$; $P=0.032$ ) in the probands, no significant associations between sclerostin levels and bone size parameters were found. The results were essentially unaltered when adjusting for lean and/or fat mass instead of weight (data not shown).

Sclerostin levels were inversely related to the serum levels of P1NP, CTX, bAP, and osteocalcin in the control group and to P1NP levels in the probands; findings, however, were lost after correcting for participant's age (data not shown). There was no difference in serum sclerostin levels between those with and without previous fractures $(P>0.22)$ in either group, and no relationship with indices of physical activity was observed (data not shown; all $P>0.19$ ). Serum

Table 2 Serum sclerostin and sex steroid levels.

\begin{tabular}{|c|c|c|c|c|c|c|}
\hline & $\begin{array}{c}\text { Probands } \\
(n=116)\end{array}$ & $\begin{array}{l}\text { Controls } \\
(n=116)\end{array}$ & $P^{*}$ & Sons $(n=40)$ & Controls $(n=40)$ & $P^{*}$ \\
\hline Sclerostin (ng/ml) & $0.54(0.41-0.66)$ & $0.61(0.51-0.78)$ & $<0.001$ & $0.52(0.41-0.62)$ & $0.54(0.45-0.66)$ & 0.31 \\
\hline $\mathrm{SHBG}(\mathrm{nmol} /)^{\mathrm{a}}$ & $29.6(22.9-37.4)$ & $25.8(20.2-37.1)$ & 0.027 & $29.4(24.3-36.9)$ & $24.9(20.4-32.5)$ & 0.14 \\
\hline Testosterone (ng/dl) & $537 \pm 163$ & $554 \pm 157$ & 0.42 & $585 \pm 179$ & $584 \pm 1690$ & 0.99 \\
\hline Free testosterone (ng/dl) & $11.5 \pm 3.8$ & $12.9 \pm 4.2$ & 0.009 & $12.8 \pm 4.3$ & $13.6 \pm 3.8$ & 0.39 \\
\hline Estradiol $\left(\mathrm{E}_{2} ; \mathrm{pg} / \mathrm{ml}\right)$ & $17.4 \pm 5.4$ & $21.9 \pm 6.2$ & $<0.001$ & $19.3 \pm 5.1$ & $20.2 \pm 5.3$ & 0.47 \\
\hline Free $E_{2}(\mathrm{pg} / \mathrm{ml})$ & $0.32 \pm 0.12$ & $0.43 \pm 0.15$ & $<0.001$ & $0.37 \pm 0.11$ & $0.40 \pm 0.11$ & 0.26 \\
\hline
\end{tabular}

Data presented as mean \pm s.D., unless ${ }^{\text {a: }}$ presented as median (1st-3rd quartiles) in the case of a non-Gaussian distribution. ${ }^{*}$ According to an independent Student's $t$-test or ${ }^{a}$ Wilcoxon signed-rank test, where appropriate. Conversion factor for testosterone from $\mathrm{ng} / \mathrm{dl}$ to $\mathrm{nmol} / \mathrm{l}$ is 0.0347 , for estradiol from $\mathrm{pg} / \mathrm{ml}$ to $\mathrm{pmol} / \mathrm{l}$ is 3.671 . 


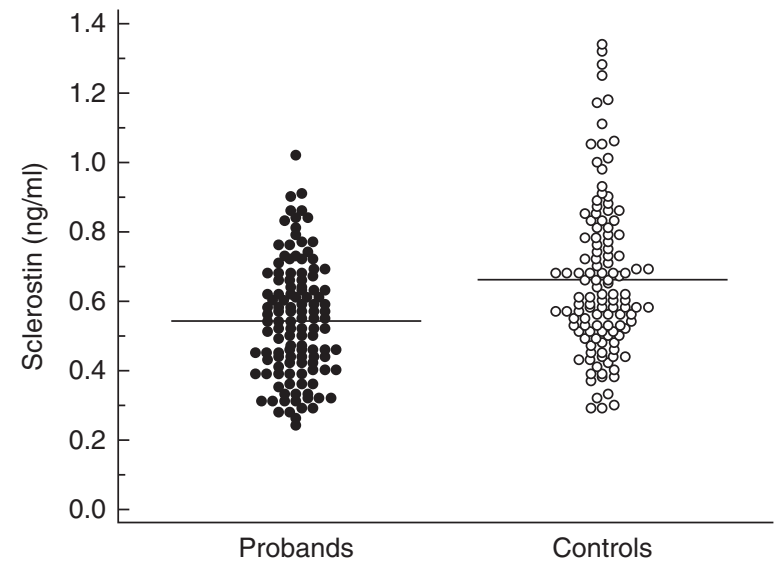

Figure 1 Dot plots of serum sclerostin levels in men with idiopathic osteoporosis and age-matched controls. The full line represents the mean.

sclerostin levels were higher in the probands taking vitamin D supplements vs those who did not $(0.57 \pm$ 0.16 vs $0.48 \pm 0.16 ; P=0.007)$, and sclerostin levels were inversely related to the eGFR in both groups $(r=-0.26 ; P=0.007$ and $r=-0.26 ; P=0.010$ respectively). These latter findings lost statistical significance when adjusting for participant's age (all $P>0.18)$.

In the probands, and in the univariate analyses in the control group, negative associations between serum sclerostin and both total $(r=-0.18 ; P=0.047)$ and free $(r=-0.20 ; P=0.031)$ testosterone levels were found. No associations with (free) $E_{2}$ or SHBG levels were found, but when controlling for testosterone levels, total $\mathrm{E}_{2}$ levels were found to be positively related to sclerostin levels $(\beta=0.20 ; P=0.039)$ in the probands only.

In the sons and their respective controls, sclerostin levels tended to be positively related to total body weight (age-adjusted $\beta=0.379 ; P=0.098$ and $\beta=0.447$; $P=0.028$ respectively), whereas no significant associations with age, bone parameters, or sex steroids were found (data not shown).

\section{Discussion}

Contrary to the initial working hypothesis, lower rather than higher serum sclerostin levels were observed in men with idiopathic low bone mass when compared with age-matched control subjects. Given that sclerostin is acknowledged as having anti-proliferative and antidifferentiating effects on osteoblasts $(3,4)$, this finding pleads against the involvement of aberrant sclerostin secretion in the pathogenesis of low bone mass in these subjects.

This between-group difference in sclerostin levels was no longer significant after adjusting for whole-body $\mathrm{BMC}$, and sclerostin levels were positively related to parameters reflecting bone strength in the probands and
- albeit to a lesser extent - in the controls. Although not unequivocally $(7,16)$, earlier studies have also reported positive associations between serum sclerostin levels and bone mass in both men and women $(5,7,8)$. These positive associations between bone mass, other parameters of bone strength, and serum sclerostin levels may seem counterintuitive since sclerostin is considered to inhibit bone formation. However, they could be explained by the fact that for the same forces applied, lower bone mass will lead to higher mechanical strain, thereby decreasing sclerostin secretion by osteocytes. Taken together, this suggests that lower serum sclerostin levels in men with idiopathic osteoporosis reflect their lower bone mass and osteocyte number or cell mass.

Corroborating previous findings $(5,7,8,9,16)$, we also found a strong positive association between serum sclerostin levels and age. Several in vivo studies have shown that mechanical loading decreases, whereas unloading increases local sclerostin production (17, $18,19)$. Since aging is associated with less physical activity and consequently mechanical loading $(20,21)$, this might at least partially explain the positive association between age and sclerostin levels.

Previous studies reported an inverse association between serum sclerostin and $\mathrm{E}_{2}$ levels in pre- and postmenopausal women (16), lower sclerostin levels in postmenopausal women under hormonal replacement therapy $(7,9)$, and an interventional study by Mödder et al. (9) demonstrated that $\mathrm{E}_{2}$ withdrawal increases serum sclerostin levels in men in whom endogenous sex steroid production was eliminated and then substituted at physiological levels. Contrary to what could be expected from these findings, total $\mathrm{E}_{2}$ levels were positively related to sclerostin levels when controlling for testosterone levels in our probands. Further, a consistent negative association was observed between sclerostin and both total and free testosterone levels in our probands, as well as in the univariate analyses in

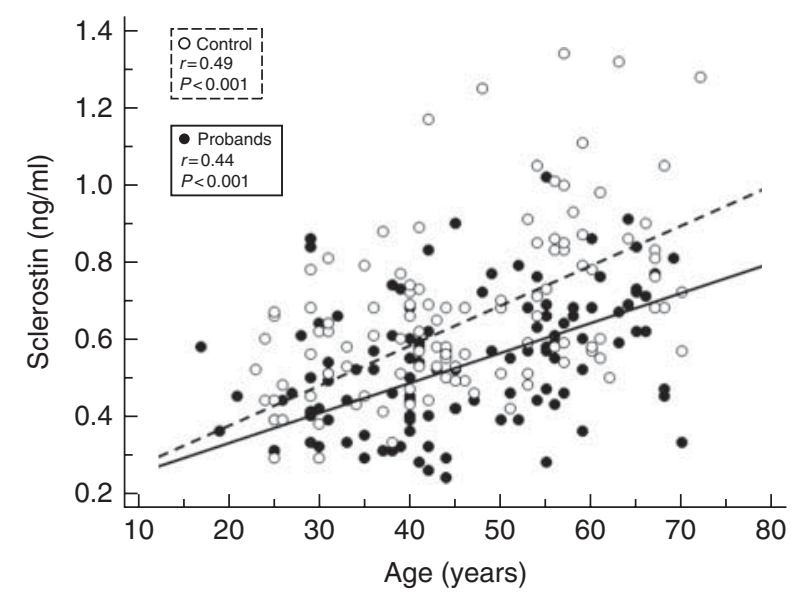

Figure 2 Scatterplots of both groups' age and serum sclerostin levels. 
Table 3 Unadjusted/age-, weight- and height-adjusted standardized regression coefficients $(\beta)$ between serum sclerostin levels and general, bone and sex steroid parameters.

\begin{tabular}{|c|c|c|}
\hline Characteristics & Probands & Controls \\
\hline Age & $0.389^{\S} / 0.475^{\S, a}$ & $0.485^{\S} / 0.472^{\S, a}$ \\
\hline Weight & $0.084 / 0.038^{b}$ & $0.197^{\star} / 0.143^{b}$ \\
\hline Height & $-0.148 / 0.071^{\mathrm{c}}$ & $-0.168 /-0.005^{\mathrm{c}}$ \\
\hline BMI & $0.142 / 0.003^{d}$ & $0.292^{\dagger} / 0.132^{d}$ \\
\hline Lean mass & $-0.030 / 0.00^{\mathrm{b}}$ & $0.027 / 0.127^{b}$ \\
\hline Fat mass & $0.158 / 0.080^{b}$ & $0.336^{\dagger} / 0.156^{b}$ \\
\hline eGFR & $-0.176 / 0.001$ & $-0.201^{\dagger} / 0.007$ \\
\hline Leptin & $0.280^{\dagger} / 0.259^{*}$ & $0.356^{\S} / 0.189$ \\
\hline Whole body BMC & $0.037 / 0.288^{\dagger}$ & $0.076 / 0.202$ \\
\hline Whole body aBMD & $0.013 / 0.267^{\dagger}$ & $0.066 / 0.194$ \\
\hline Lumbar spine BMC & $-0.081 / 0.165$ & $0.018 / 0.114$ \\
\hline Lumbar spine aBMD & $-0.152 / 0.088$ & $0.014 / 0.049$ \\
\hline Total hip BMC & $-0.140 /-0.166$ & $0.068 / 0.133$ \\
\hline Total hip aBMD & $-0.150 /-0.072$ & $0.064 / 0.247^{*}$ \\
\hline Radius BMC & $0.048 / 0.044$ & $0.012 /-0.008$ \\
\hline Radius aBMD & $-0.007 / 0.116$ & $0.023 / 0.047$ \\
\hline Radius trab. BMC & $0.103 / 0.111$ & $0.039 / 0.038$ \\
\hline Radius trab. vBMD & $0.012 / 0.165$ & $0.042 / 0.079$ \\
\hline Radius cort. BMC & $0.010 / 0.070$ & $0.065 / 0.093$ \\
\hline Radius cort. vBMD & $-0.113 / 0.078$ & $-0.079 / 0.171$ \\
\hline Tibia trab. BMC & $0.088 / 0.222^{*}$ & $0.067 / 0.136$ \\
\hline Tibia trab. vBMD & $0.024 / 0.276^{\dagger}$ & $0.055 / 0.129$ \\
\hline Tibia cort. BMC & $0.016 / 0.100$ & $0.066 /-0.001$ \\
\hline Tibia cort. vBMD & $0.049 / 0.227^{*}$ & $-0.112 / 0.228$ \\
\hline Estradiol & $0.071 / 0.110$ & $-0.046 / 0.106$ \\
\hline Free estradiol & $-0.036 / 0.008$ & $0.003 / 0.086$ \\
\hline Testosterone & $-0.186^{\star} /-0.184^{\star}$ & $-0.208^{*} /-0.018$ \\
\hline Free trestosterone & $-0.311^{\dagger} /-0.202^{*}$ & $-0.183 / 0.010$ \\
\hline SHBG & $0.066 /-0.145$ & $-0.096 /-0.167$ \\
\hline
\end{tabular}

${ }^{\star} P<0.05,{ }^{\dagger} P<0.01$ and ${ }^{\S} P<0.001 . \mathrm{E}_{2}$, estradiol.

${ }^{a}$ Adjusted for weight and height.

${ }^{\mathrm{b}}$ Adjusted for age and height.

${ }^{\mathrm{c}}$ Adjusted for age and weight.

${ }^{\mathrm{d} A d j u s t e d}$ for age.

the control group. These findings are in line with cross-sectional studies reporting a positive association between serum $\mathrm{E}_{2}$ and sclerostin levels in older men $(7,8)$ and a negative association between bioavailable testosterone and sclerostin levels in a middle-aged subgroup (40-59 years) (7). These inconsistent findings are difficult to explain but might result from differences in participants' conditions, leading to different sex hormone levels and/or increased bone remodeling.

The strengths of our study are the well-described patient population of men with idiopathic osteoporosis, together with their well-characterized phenotype. Limitations are the limited sample size and the fact that male idiopathic osteoporosis might represent a spectrum of low bone mass due to heterogeneous mechanisms and different causes. Given the age of our probands and controls, we cannot extrapolate the role of sclerostin during peak bone mass acquisition. However, given that no differences in sclerostin levels were observed between their sons (whether they were affected or not) and agematched controls, a primary role for sclerostin in the deficient bone acquisition process in men with idiopathic osteoporosis seems unlikely.
In conclusion, this study shows that serum sclerostin levels in men with idiopathic osteoporosis are lower than those in healthy control subjects, possibly reflecting differences in overall bone mass. Although further research is needed, aberrant sclerostin secretion seems unlikely to be causally involved in the pathogenesis of idiopathic osteoporosis in men.

\section{Declaration of interest}

The authors declare that there is no conflict of interest that could be perceived as prejudicing the impartiality of the research reported.

\section{Funding}

This work was supported by grants G0662.07 and G0867.11 from 'Fonds voor Wetenschappelijk Onderzoek - Vlaanderen (FWO; Research Foundation - Flanders)' and by an unrestricted grant of Novartis Belgium. Y Taes is a postdoctoral fellow and S Vandewalle is a doctoral fellow of the FWO.

\section{Author contribution statement}

All authors participated in the writing of the manuscript; S Goemaere, $\mathrm{H}$ Zmierczak, and J M Kaufman designed the study; S Goemaere, $\mathrm{H}$ Zmierczak, J M Kaufman, S Vandewalle, Y Taes, and B Lapauw recruited the subjects; $\mathrm{Y}$ Taes and J M Kaufman were responsible for all laboratory measurements except for sclerostin which was measured in the laboratory of J Collette.

\section{Acknowledgements}

We are indebted to S Geboes, K Toye, K Mertens, and I Bocquaert for their excellent technical assistance.

\section{References}

1 World Health Organization. Diet, nutrition, and the prevention of chronic diseases. World Health Report TRS 916, 2003.

2 Kaufman JM \& Goemaere S. Osteoporosis in men. Best Practice \& Research. Clinical Endocrinology \& Metabolism 200822 787-812. (doi:10.1016/j.beem.2008.09.005)

3 Moester MJ, Papapoulos SE, Lowik CW \& van Bezooijen RL. Sclerostin: current knowledge and future perspectives. Calcified Tissue International 201087 99-107. (doi:10.1007/s00223-0109372-1)

4 Monroe DG, Gee-Lawrence ME, Oursler MJ \& Westendorf JJ. Update on Wnt signaling in bone cell biology and bone disease. Gene 2012 492 1-18. (doi:10.1016/j.gene.2011.10.044)

5 Amrein K, Amrein S, Drexler C, Dimai HP, Dobnig H, Pfeifer K, Tomaschitz A, Pieber TR \& Fahrleitner-Pammer A. Sclerostin and its association with physical activity, age, gender, body composition, and bone mineral content in healthy adults. Journal of Clinical Endocrinology and Metabolism 201297 148-154. (doi:10.1210/jc.2011-2152)

6 Mirza FS, Padhi ID, Raisz LG \& Lorenzo JA. Serum sclerostin levels negatively correlate with parathyroid hormone levels and free estrogen index in postmenopausal women. Journal of Clinical Endocrinology and Metabolism 201095 1991-1997. (doi:10.1210/jc.2009-2283)

7 Mödder UI, Hoey KA, Amin S, McCready LK, Achenbach SJ, Riggs BL, Melton LJ \& Khosla S. Relation of age, gender, and bone 
mass to circulating sclerostin levels in women and men. Journal of Bone and Mineral Research 201126 373-379. (doi:10.1002/jbmr.217)

8 Szulc P, Bertholon C, Borel O, Marchand F \& Chapurlat R. Lower fracture risk in older men with higher sclerostin concentration - a prospective analysis from the MINOS study. Journal of Bone and Mineral Research 2013 In press. (doi:10.1002/jbmr.1823)

9 Mödder UI, Clowes JA, Hoey K, Peterson JM, McCready L, Oursler MJ, Riggs BL \& Khosla S. Regulation of circulating sclerostin levels by sex steroids in women and in men. Journal of Bone and Mineral Research 201126 27-34. (doi:10.1002/ jbmr.128)

10 Van Pottelbergh I, Goemaere S, Zmierczak H \& Kaufman JM. Perturbed sex steroid status in men with idiopathic osteoporosis and their sons. Journal of Clinical Endocrinology and Metabolism 200489 4949-4953. (doi:10.1210/jc.2003-032081)

11 Lapauw B, Taes Y, Goemaere S, Toye K, Zmierczak HG \& Kaufman JM. Anthropometric and skeletal phenotype in men with idiopathic osteoporosis and their sons is consistent with deficient estrogen action during maturation. Journal of Clinical Endocrinology and Metabolism 200994 4300-4308. (doi:10.1210/jc.2009-0568)

12 Baecke JA, Burema J \& Frijters JE. A short questionnaire for the measurement of habitual physical activity in epidemiological studies. American Journal of Clinical Nutrition 198236 936-942.

13 Fiers T, Casetta B, Bernaert B, Vandersypt E, Debock M \& Kaufman JM. Development of a highly sensitive method for the quantification of estrone and estradiol in serum by liquid chromatography tandem mass spectrometry without derivatization. Journal of Chromatography. B, Analytical Technologies in the Biomedical and Life Sciences 2012 893-894 57-62. (doi:10.1016/ j.jchromb.2012.02.034)

14 Vermeulen A, Verdonck L \& Kaufman JM. A critical evaluation of simple methods for the estimation of free testosterone in serum. Journal of Clinical Endocrinology and Metabolism $1999 \mathbf{8 4}$ 3666-3672. (doi:10.1210/jc.84.10.3666)

15 Szulc P, Claustrat B, Munoz F, Marchand F \& Delmas PD. Assessment of the role of $17 \beta$-oestradiol in bone metabolism in men: does the assay technique matter? The MINOS study Clinical Endocrinology 200461 447-457. (doi:10.1111/j.1365-2265. 2004.02117.x)

16 Ardawi MS, Al-Kadi HA, Rouzi AA \& Qari MH. Determinants of serum sclerostin in healthy pre- and postmenopausal women. Journal of Bone and Mineral Research $2011262812-2822$. (doi:10.1002/jbmr.479)

17 Robling AG, Niziolek PJ, Baldridge LA, Condon KW, Allen MR, Alam I, Mantila SM, Gluhak-Heinrich J, Bellido TM, Harris SE et al. Mechanical stimulation of bone in vivo reduces osteocyte expression of Sost/sclerostin. Journal of Biological Chemistry 2008 283 5866-5875. (doi:10.1074/jbc.M705092200)

18 Spatz JM, Fields EE, Yu EW, Pajevic PD, Bouxsein ML, Sibonga JD, Zwart SR \& Smith SM. Serum sclerostin increases in healthy adult men during bed rest. Journal of Clinical Endocrinology and Metabolism 201297 E1736-E1740. (doi:10. 1210/jc.2012-1579)

19 Lin C, Jiang X, Dai Z, Guo X, Weng T, Wang J, Li Y, Feng G, Gao X \& He L. Sclerostin mediates bone response to mechanical unloading through antagonizing Wnt/ $\beta$-catenin signaling. Journal of Bone and Mineral Research 200924 1651-1661. (doi:10.1359/jbmr. 090411)

20 Norman A, Bellocco R, Vaida F \& Wolk A. Total physical activity in relation to age, body mass, health and other factors in a cohort of Swedish men. International Journal of Obesity and Related Metabolic Disorders 200226 670-675. (doi:10.1038/sj.ijo. 0801955)

21 Anokye NK, Pokhrel S, Buxton M \& Fox-Rushby J. Physical activity in England: who is meeting the recommended level of participation through sports and exercise? European Journal of Public Health 2013 In press. (doi:10.1093/eurpub/cks127)

Received 12 December 2012

Revised version received 28 January 2013

Accepted 6 February 2013 